\section{A FORMAÇÃO DO PROFESSOR DE EDUCAÇÃO FÍSICA: DA DIDÁTICA DAS DISCIPLINAS AO CONHECIMENTO DO ENSINO}

\author{
TRAINING OF PHYSICAL EDUCATION TEACHERS: FROM DIDACTICS \\ OF SUBJECTS TO KNOWLEDGE OF TEACHING C
}

LA FORMACIÓN DEL PROFESOR DE EDUCACIÓN FÍSICA: DE LA

DIDÁCTICA DE LAS ASIGNATURAS AL CONOCIMIENTO DE LA

ENSEÑANZA C P

doi' https://doi.org/10.22456/1982-8918.106849

(D) Reiner Hildebrandt-Stramann* <r.hildebrandt-stramann@tu-bs.de>

Amauri Aparecido Bássoli de Oliveira** <amauribassoli@gmail.com>

Marli Hatje ${ }^{* * *}<$ hatjemarli@gmail.com>

Luciana Erina Palm***<luepalma@yahoo.com.br>

\footnotetext{
*Technische Universität Braunschweig. Braunschweig, Alemanha.

**Universidade Estadual de Maringá. Maringá, PR, Brasil. Universidad Católica del Maule (UCM). Talca, Chile.

***Universidade Federal de Santa Maria. Santa Maria, RS, Brasil.
}

\begin{abstract}
Resumo: O artigo discute sobre a profissionalização em ciências da educação e sua relação com a formação universitária de professores de Educação Física. São consideradas três hipóteses que devem ser superadas no contexto de um desenvolvimento curricular: a diferença entre ciência da disciplina e didática da disciplina; a diferença entre o conhecimento biográfico, as expectativas dos estudantes de Educação Física e o conhecimento da disciplina que deve ser transmitido; e a diferença entre a didática das disciplinas e o conhecimento do ensino ou a transformação do conhecimento didático das disciplinas em conhecimento do ensino. Para exemplificar a discussão é apresentada uma proposta curricular modularizada à formação de professores de Educação Física, elaborada pelos autores durante o desenvolvimento de um projeto curricular internacional e, na sequência, um Módulo com o objetivo de mostrar sua estrutura baseada na teoria educacional da autoeducação e na teoria dialógica do movimento.
\end{abstract}

Palavras chave: Currículo. Formação em Educação Física. Licenciatura.
Recebido em: 26 ago. 2020 Aprovado em: 07 mar. 2021 Publicado em: 03 abr. 2021

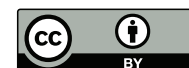

Este é um artigo publicado sob a licença Creative Commons Atribuição 4.0 Internacional (CC BY 4.0).

eISSN: 1982-8918 


\section{INTRODUÇÃO}

Atuar como professor de Educação Física na escola exige que se tenha uma formação universitária na área da licenciatura e essa formação não se configura como uma ação simples e tranquila. Ao contrário, ela é integrada à lógica institucional de uma universidade que se vincula à ideia de ciência e que confronta os estudantes com a expectativa de projetar seus próprios processos de aprendizagem com base no pensamento científico e teórico. No entanto, a formação universitária de futuros professores sempre vai além do pensamento científico da universidade, ela objetiva preparar os estudantes para sua futura prática profissional em uma escola e, portanto, para uma atividade profissional que siga sua própria lógica.

Nesse sentido, não nos parece possível discutir a formação de professores sem abordar a tensão existente nessa relação entre estudo e profissão, entre ciência e prática. Desde o surgimento da formação profissional institucionalizada e, assim, organizada para professores no século XIX, as reformas na formação de professores sempre estiveram ligadas à questão de como determinar exatamente a relação entre teoria e prática nessa formação.

Outro problema se coloca na Educação Física como uma formação universitária. Nossa experiência cotidiana no ensino demonstra que os estudantes não veem quase nenhum valor para si e para o seu futuro campo profissional ao lidar com o conteúdo didático e a ciência dessa disciplina. Contudo, sua avaliação é sustentada por um currículo universitário caracterizado pela justaposição não relacionada de seminários práticos, didáticos e científicos (HILDEBRANDT-STRAMANN; HATJE; PALMA; OLIVEIRA, 2020). Por outro lado, a avaliação dos estudantes apoiadas em suas experiências biográficas os satisfazem, acima de tudo, por considerar que suas próprias habilidades de movimento para ensinar a Educação Física na escola e que suas experiências de mediação, que eles adquiriram na escola e, sobretudo no clube esportivo, se apresentam como suficientes. Esse comportamento avaliativo impacta diretamente no conhecimento da experiência prática cotidiana que orienta as ações, domina o conhecimento especializado (da disciplina científica Educação Física) e dificulta a compreensão da importância da teoria em um processo formativo em nível superior.

A formação de professores universitários tem que lidar com os dois problemas, uma vez que os currículos tradicionais não só não resolvem os problemas, mas os reforçam - como indicado anteriormente. Isso reforça a ideia da necessidade de se pensar na nova concepção dos currículos para a formação de professores de Educação Física. Do ponto de vista epistemológico, há um duplo problema de teoriaprática na construção de currículos para a formação de professores de Educação Física: o primeiro problema é a diferença entre a relação científica com o mundo da universidade e o segundo da relação prática com o mundo da escola.

A compreensão dessas duas áreas problemáticas (a relação científica e a relação prática) é um dos vários pontos de partida para a legitimação de um novo modelo curricular que os autores deste artigo desenvolveram como parte de um projeto curricular internacional para a formação de futuros professores de Educação Física na Universidade Federal de Santa Maria (UFSM). Este modelo de um currículo 
modularizado é apresentado nas Figuras 1 e 2, as considerações são esboçadas exemplificando como o problema dual teoria-prática pode ser encaminhado pedagogicamente.

\section{A DIFERENÇA ENTRE CIÊNCIA NA UNIVERSIDADE E ORIENTAÇÃO À AÇÃO NA ESCOLA}

A universidade se coloca como um lugar da ciência, no qual o conhecimento científico é produzido e disseminado junto aos estudantes, sendo o processo de aquisição de conhecimento científico denominado de pesquisa e o processo de transmissão como ensino. Pesquisa e ensino são duas das principais tarefas das universidades modernas. Quando os estudantes vêm da escola para a universidade, eles precisam ser introduzidos a esse mundo da pesquisa e ensino. Do ponto de vista científico-teórico, trata-se de uma introdução a um tipo específico de encontro no mundo: pesquisando o mundo de maneira qualitativa, quantitativa ou hermenêutica, explicando o mundo com a ajuda de teorias, lidando com teorias discursivamente.

Toda disciplina escolar, que pode ser estudada na universidade, tem sua própria base científica, ou seja, possui suas próprias teorias para explicar o mundo. Portanto, a matemática tem sua própria teoria, assim como história ou até mesmo a Educação Física. Os estudantes têm que estudar esse corpo teórico para adquirir um conhecimento especializado sobre ele e, portanto, uma competência especializada da disciplina.

A escola se coloca como um mundo de transmissão de conhecimento. No entanto, não apenas o conhecimento científico em específico, mas um conjunto deles vinculados a várias áreas de conhecimento. Isso se replica na universidade, sendo quase os mesmos conhecimentos, mas em contraste com a universidade, os conhecimentos na escola são preparados pedagogicamente. Isto é, os estudantes devem aprender na universidade os conhecimentos científicos, que são os pressupostos dos conhecimentos didáticos.

O cerne dos conhecimentos didáticos é a transformação didática do conhecimento científico da ciência da disciplina (em nosso caso a ciência da Educação Física). Este conhecimento transformado deve ser o conteúdo que o professor transmite para os alunos na escola. A principal tarefa do professor na escola é iniciar processos de aprendizagem, da compreensão e da educação para os alunos. Para que o professor seja capaz de cumprir essa tarefa, ele adquire competências durante os estudos para transformar seu conhecimento científico da disciplina de forma que processos apropriados de aprendizagem, da compreensão e da educação possam ser aplicados junto aos alunos. No ensino universitário, esse conhecimento é entendido como conhecimento didático relacionado à disciplina. $\mathrm{O}$ conhecimento didático moderno relacionado à disciplina é projetado para iniciar processos de aprendizagem na escola com os quais o aluno atua ativamente gerando conhecimento sobre o mundo ${ }^{1}$. Para tanto, denominamos este conhecimento didático relacionado à 
disciplina também como "conhecimento de transformação". O conhecimento didático relacionado à disciplina, portanto, depende de seu conhecimento científico. Isso significa que um futuro professor deve adquirir conhecimento em ambas as formas de conhecimento dentro de um processo formativo para poder cumprir sua futura atuação na educação e desenvolver a aprendizagem na escola.

Nossas observações na universidade mostram que os estudantes têm grande dificuldade e/ou uma resistência em adquirir as duas formas de conhecimento. Suas experiências biográficas são baseadas em conhecimentos escolares que foram mais ou menos desenvolvidas pelo professor. Esse conhecimento escolar geralmente é uma forma abreviada do respectivo conhecimento da disciplina. Uma transformação didática raramente ocorre porque os professores também têm poucas competências de transformação didática. Isso significa que geralmente não é solicitado aos alunos que ajam e, assim, gerem ativamente seus conhecimentos, mas que permaneçam em uma posição receptiva durante o processo de aprendizagem. Com essa biografia receptiva eles chegam à universidade mantendo sua postura receptiva, pois os processos de aprendizagem - também na universidade - são projetados de maneira receptiva. Esse status quo inicialmente tem duas consequências:

a) Os estudantes devem adquirir os conhecimentos científicos da disciplina e seus conhecimentos didáticos durante os estudos. Isso implica que os seminários científicos da disciplina e de sua didática devem estar vinculados e/ou relacionados, demonstrando clareza nas conexões entre o conhecimento científico da disciplina e o seu conhecimento didático.

b) Os estudantes alunos precisam aprender a superar e mudar suas atitudes receptivas adquiridas biograficamente ao adquirir conhecimento. Para esse fim, as disciplinas universitárias devem ser ensinadas de forma orientada para a ação, ou seja, os alunos devem estar envolvidos ativamente nos processos de pesquisa e processos de solução de problemas delas.

\subsection{A DIFERENÇA ENTRE A MEDIAÇÃO ORIENTADA NA TEORIA DAS HABILIDADES PRÁTICAS DE ENSINO DA EDUCAÇÃO FÍSICA E A DAS HABILIDADES PRÁTICAS DE MOVIMENTO}

O estudo da profissão de professor de Educação Física nas escolas é como já mencionado inicialmente -, além das duas diferenças descritas até agora, determinada por outra diferença, que específicamente se aplica aos alunos da disciplina Educação Fisica. É a diferença entre a reivindicação da universidade de uma transmissão baseada na teoria de habilidades práticas de ensino e a imagem determinada biograficamente de um estudante de Educação Física sobre os objetivos de estudo e o conteúdo do curso.

Os estudantes de Educação Física geralmente optam por um curso universitário de Educação Física devido à sua própria prática esportiva, normalmente bemsucedida. Para a maioria dos estudantes de Educação Física, a questão relacionada ao estudo esportivo está determinada: eles estudam "esportes". No curso universitário de Educação Física, o "esporte" é reproduzido. 
Esta biografia esportiva determina as ideias de um estudante de Educação Física sobre seus estudos. Os estudos esportivos, via de regra, são para melhorar as habilidades de movimento esportivo e transmitir habilidades de movimento esportivo com sentido no treinamento. Como os estudantes de Educação Física já têm conhecimento de ambas as áreas, a opinião predominante é de que os estudos esportivos apenas podem fornecer-Ihes pouco conhecimento novo. Afinal, eles são "profissionais do esporte" devido à sua experiência esportiva na escola e em instituições específicas do esporte, como clubes esportivos ou academias. Como resultado, há pouca motivação para lidar com questões de pesquisa, ciência ou didática. O currículo tradicional da formação de futuros professores de Educação Física geralmente reforça essa biografia. Como resultado, as técnicas de movimento se replicam na Educação Física da escola, ensinada no sentido de um curso metódico baseado no princípio metódico "do fácil ao difícil, do simples ao complexo, das partes para o todo" (MEINEL, 1984, p. 171). A justificativa teórica para esse procedimento é geralmente baseada em teorias tecnocráticas da aprendizagem que, em geral, podem ser entendidas pelos alunos por causa das suas experiências biográficas.

No entanto, a maioria dos estudantes de Educação Física ignora o fato de que neste estudo se trata menos da melhoria do rendimento atlético individual, visto que no curso universitário de Educação Física o conhecimento é adquirido pela ciência do esporte ${ }^{2}$, com a ajuda da qual eles devem estar teórica e praticamente preparados para sua profissão. Isso se aplica, acima de tudo, à profissão do professor de Educação Física Escolar.

As diferenças entre as demandas dos estudos universitários por parte da universidade e as dos alunos tornam-se claras: O habitus específico da disciplina dos alunos é o habitus esportivo, orientado para a aplicação. Isso se aplica tanto ao assunto de estudos da Educação Física (esportes) quanto à transmissão de conteúdo (iniciação de processos de aprendizagem tecnocrático com base em técnicas de movimento).

Com relação à conexão entre a ciência da disciplina e a didática da disciplina, a biografia esportiva do estudante representa a existência implícita de experiência, que determina claramente a luta com as existências de conhecimentos didáticos e científicos da disciplina na universidade. Para a profissionalização de futuros professores de Educação Física surge a questão de como não deixar a experiência específica do esporte (o conhecimento biográfico) se tornar uma limitação, mas sim um recurso para a ação didática por meio da reflexão e da expansão do conhecimento. Entre outras coisas, essa inquietação orientou uma proposta curricular desenvolvida por Hildebrandt-Stramann e Taffarel (2017) para a formação de futuros professores de Educação Física na UFBA e por Hildebrandt-Stramann, Hatje, Palma e Oliveira (2020) para a formação de futuros professores de Educação Física na UFSM. Como as duas propostas curriculares são semelhantes, optamos por apresentar apenas a proposta da UFSM. 


\section{A PROPOSTA CURRICULAR PARA A FORMAÇÃO DOS ESTUDANTES DA EDUCAÇÃO FÍSICA NO CURSO DE LICENCIATURA NA UFSM}

O currículo de formação de professores tem como objetivo a profissionalização dos estudantes. Mas o que significa profissionalização? Antes de introduzirmos o modelo curricular, a questão da profissionalização deve ser respondida com referência às três áreas problemáticas identificadas, sendo: problema da biografia; problema dos conhecimentos didáticos e da transformação didática; problema do conhecimento científico da disciplina.

Problema da biografia. Se os estudantes de esportes iniciam seus estudos com uma biografia esportiva e se ambicionam para uma profissão de professor de Educação Física Escolar, então nos parece necessário expandir essa biografia esportiva, pois ela vem acompanhada de uma visão limitada do campo do movimento, dos jogos e do esporte. Nesse contexto, profissionalização deve significar aprender a se distanciar da própria biografia esportiva e se tornar um especialista em sua disciplina. Para ser um especialista, o futuro professor precisa ter a capacidade de refletir sobre o tema principal da Educação Física. Estamos nos referindo aqui à discussão da questão do objeto de estudo em Educação Física: objeto é o movimento esportivo ou o movimento humano? (TREBELS, 1992; KUNZ, 2010, p. 11-22). A questão é de crucial importância, pois a opção por uma ou outra resposta tem implicações educacionais que se refletem concretamente no tipo de encenação de ensino da Educação Física e sua repercussão nos processos de aprendizagem do movimento.

Para que os alunos conheçam os requisitos acadêmicos de uma universidade (problema da diferença entre a universidade e o mundo escolar), eles precisam adquirir conhecimento sobre várias teorias das ciências do esporte (por exemplo, conhecimento da ciência do treinamento, ciência do movimento, ciências sociais, teorias das ciências educacionais), adquirir conhecimentos sobre as diferenças epistemiológicas e também as conexões entre as teorias individuais inclusas nas áreas teóricas.

Problema dos conhecimentos didáticos e da transformação didática. Para um professor de Educação Física, o conhecimento teórico é absolutamente necessário, mas não suficiente. Ele precisa aprender a refletir sobre os objetivos, conteúdos e as abordagens metodológicas. Isto é, o estudante deve adquirir a capacidade de questionar o conteúdo especializado e as abordagens metodológicas, assim como os seus pré-requisitos epistemológicos e sua intermediação. Porque esta é a tarefa original da didática da Educação Física, os estudantes precisam ter conhecimentos didáticos que vão além dos conhecimentos científicos (conhecimentos da ciência da disciplina e conhecimentos da didática da disciplina que possibilitem arranjos os mais variados possíveis). Além disso, um professor da Educação Física precisa ter a capacidade de transformar os fenômenos do esporte em temas didáticos, que podem ser ensinados nas aulas de Educação Física ${ }^{3}$. Esta capacidade baseiase num tipo de configuração de formação, tendo o estudo como um "processo de transformação". Esta capacidade de "transformação didática" implica a capacidade

3 Isso também se aplica, por exemplo, a conceitos na ciência do treinamento. Por exemplo, os alunos precisam da competência de transformação didática, com base na qual o conhecimento das ciências de treinamento pode ser transformado em um conhecimento pedagógico-didático de treinamento (HILDEBRANDT-STRAMANN; TAFFAREL, 2017, p. 217-238). 
de reflexão baseada em teorias. Aqui podemos citar as teorias pedagógico-didáticas (por exemplo, em abordagens didáticas orientadas para o esporte versus concepções didáticas): "Educação Física crítico-emancipatória" (KUNZ; TREBELS, 2010); do "Ensino-aprendizagem aberto às experiências" (HILDEBRANDT-STRAMANN, 2009). As teorias de aprendizagem relacionadas ao movimento como "abordagens dialógicas" (TREBELS, 2010), as teorias do Gestalt, como, por exemplo, "reflexões teóricas da percepção" (WEIZSÄCKER, 1968) ou reflexões sobre a "aprendizagem e um ensino genético" (BECKMANN; HILDEBRANDT-STRAMANN; WICHMANN, 2009, p. 31-44) e suas consequências para a prática das aulas de Educação Física 4 .

Problema do conhecimento científico da disciplina. Uma competência profissional também inclui a habilidade de realizar estudos científicos intensivos e a capacidade de saber pesquisar, isto é, por exemplo, de organizar e realizar estudos empíricos sobre o significado de movimento no ensino e na escola.

\subsection{A PROPOSTA CURRICULAR}

A proposta curricular configura-se como um currículo modularizado ${ }^{5}$. O currículo contém dez módulos para os dois primeiros anos e sete módulos para os dois últimos anos. O conceito de movimento faz parte do tópico de praticamente todos os módulos. Isso torna clara a base pedagógica do movimento do modelo curricular, que se baseia em uma compreensão fenomenológica do movimento. Nesse sentido, o assunto do estudo é factível para um futuro professor de Educação Física na estrutura curricular: o objeto de estudo é o movimento humano (FIGURA 1).

Figura 1 - Módulos dos quatro semestres iniciais: comuns (C) para Bacharelado (B) e Licenciatura (L)

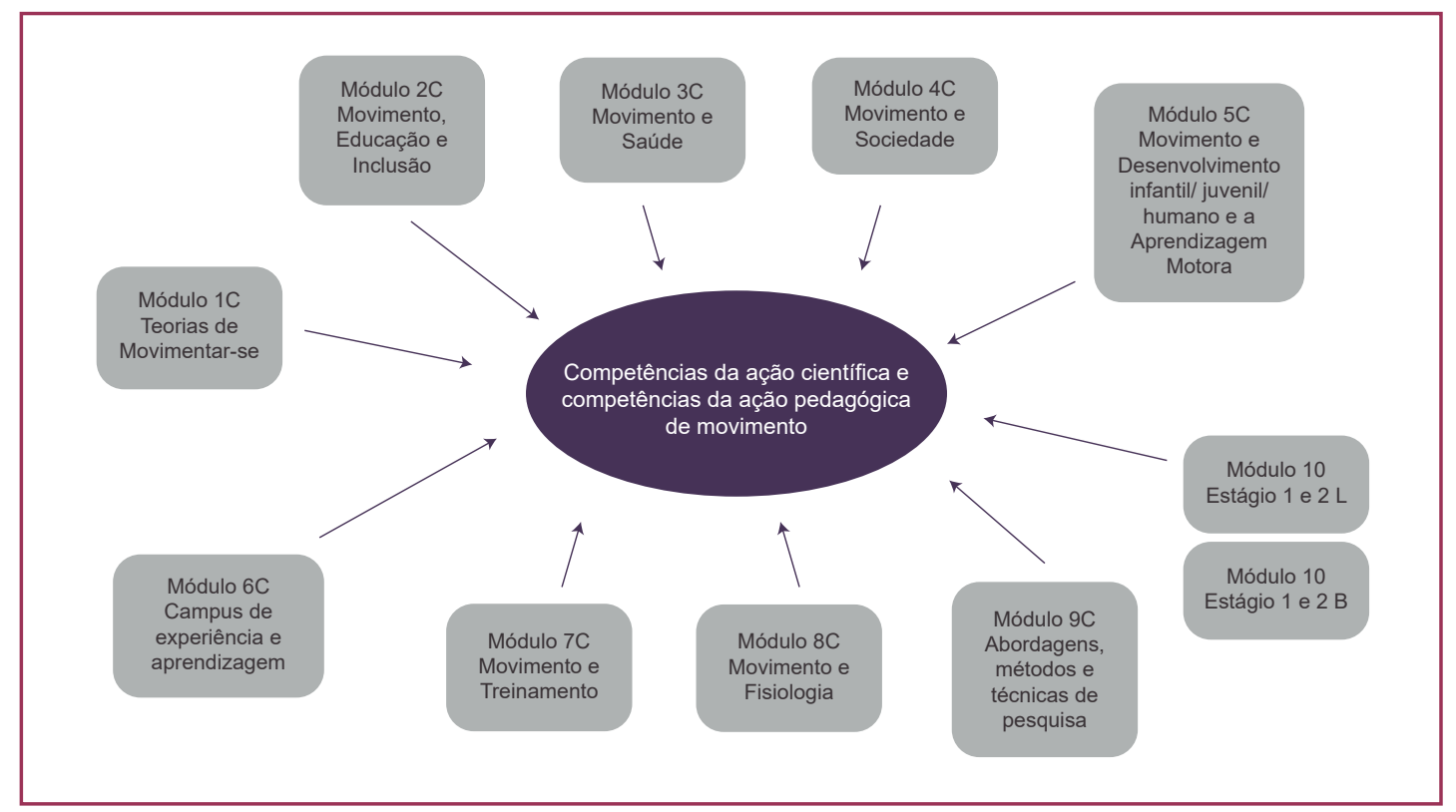

Fonte: os autores

\footnotetext{
4 Essa discussão didática entre "teorias do movimento humano" e "teorias do movimento do esporte" está representada principalmente na didática do movimento brasileiro nas publicações de Trebels (1992), Kunz (2010), Kunz; Costa (2016) e Hildebrandt-Stramann (2013).

5 Esse modelo de formação tem sido adotado com sucesso na Alemanha em longa data e está em elaboração e implantação gradual no curso de Educação Física da Universidade Federal de Santa Maria - UFSM, tendo por base o referencial aqui apresentado. Espera-se que os indicativos apresentados possam suscitar novas e profícuas reflexões e propostas de organização curricular na formação em Educação Física no Brasil.
} 
Figura 2 - Módulos do quinto ao oitavo semestre, específicos da Licenciatura (L)

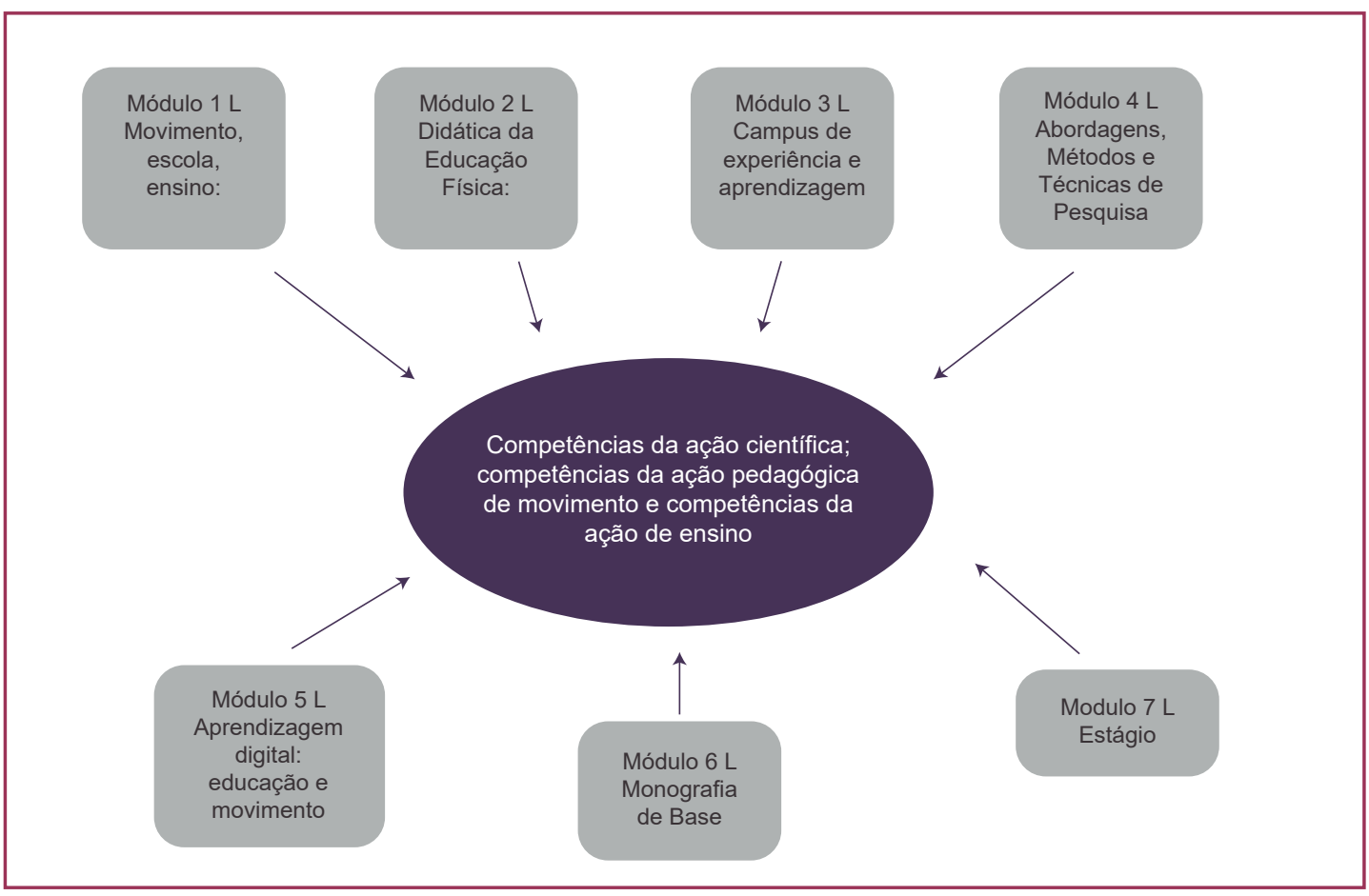

Fonte: os autores

Cada módulo contém pelo menos três seminários (Quadro 1), sendo que em um seminário acontece uma introdução científica disciplinar no tópico do módulo, em um segundo seminário uma base didática disciplinar e em um terceiro seminário uma transformação didática com uma referência de movimento. Portanto, o terceiro seminário deve sempre consistir em um dos campos de movimento ${ }^{6}$ mencionados no currículo (veja o módulo $6 \mathrm{C}$ e o módulo $3 \mathrm{~L}$ ). Com esta estrutura de módulos, as conexões entre ciência da disciplina ( $1^{\circ}$ seminário), didática da disciplina $\left(2^{\circ}\right.$ seminário) e prática de movimento ( $3^{\circ}$ seminário) devem ser esclarecidas para os estudantes, impedindo o desenvolvimento de conhecimentos ecléticos. Do ponto de vista epistemológico trata-se de conhecer, em um módulo, diferentes acessos ao mundo e, portanto, também conhecer níveis específicos de cognição: na ciência da disciplina, trata-se de um acesso teórico ao mundo de modo reflexivo, na didática da disciplina, trata-se de um acesso refletido teoricamente na ação e, na prática da disciplina, trata-se de um acesso corporalmente reflexivo ao mundo ${ }^{7}$. A seguir vamos esclarecer a estrutura e os conteúdos num exemplo do módulo 2 B "movimento, educação e inclusão".

\footnotetext{
6 Os campi de movimento não são disciplinas esportivas, mas sim campi de movimento como "correr, saltar, lançar"; Movimentar-se com e sem aparelhos; Movimentar-se na água; lutar; culturas tradicionais de movimento; Jogar; Jogar em equipes; Expressar-se por meio de movimento (HILDEBRANDT-STRAMANN; HATJE; PALMA; OLIVEIRA, 2020, p. 46).

7 Um dos objetivos do módulo 10 Estágio 1 e $2 \mathrm{~L}$ é trabalhar com os alunos na teoria biográfica. Para que os alunos sejam conscientes da sua biografia, seriam necessários, pelo menos, três seminários nas seguintes etapas: 1. uma etapa na qual os estudantes aprendem a analisar aulas tradicionais da Educação Física; 2. uma etapa de planejamento das aulas de Educação Física segundo a concepção didática das aulas abertas à experiência (HILDEBRANDT-STRAMANN, 2009); e 3. uma etapa da realização das aulas planejadas nas escolas (confira aqui os exemplos no livro de Hildebrandt-Stramann e Taffarel, 2017).
} 


\subsection{O MÓDULO 2 C "MOVIMENTO, EDUCAÇÃO E INCLUSÃO”8}

Os fundamentos científicos da disciplina ( $1^{\circ}$ seminário) deste módulo já estão predeterminados pelo tópico introdutório do módulo: no primeiro seminário deste módulo, os alunos lidam com a literatura sobre teorias da educação e do movimento. As teorias educacionais são, por exemplo, teorias antropológicas, teorias da ação, filosóficas, empíricas, hermenêuticas e críticas da educação. As teorias de movimento tratam das visões científicas naturais (por exemplo, teorias sensório-motoras, modelos cibernéticos, teoria morfológica), antropológico-psicológicas (por exemplo, o modelo da psicomotricidade), fenomenológicas e pedagógicas do movimento (teoria do Gestalt, teoria da percepção, teoria das relações entre "stimulus-response-effect-relations" (estímulo-resposta-efeito-relações), teoria dialógica de movimento.

A tarefa didática do professor universitário responsável pelo módulo é a de selecionar uma literatura educacional e uma literatura da ciência do movimento que possibilite aos alunos reconhecer a articulação epistemológica e, posteriormente, a didática das várias conexões teóricas.

A linguagem científica refere-se ao "contexto de implicação das decisões didáticas” (HILDEBRANDT-STRAMANN, 2016, p. 50-51). Qualquer escolha de teoria levaria a uma visão eclética dos tópicos da ciência do esporte entre os alunos. Mas é exatamente isso que deve ser evitado. Por exemplo, se o líder do seminário seleciona a teoria crítica como uma teoria educacional científica, então é importante trabalhar claramente o objetivo educacional dessa teoria, ou seja, a promoção da autoeducação. Em termos do contexto de implicações, no nível da teoria do movimento, é a teoria do movimento dialógico que explica a subjetividade de aprender a mover-se e, portanto, é compatível com o objetivo educacional da autoeducação.

No plano didático, são os conceitos didáticos da "didática crítico-emancipatória" e da "didática do ensino aberto" que se fundamentam na compreensão da educação como autoeducação e na compreensão do movimento como diálogo entre o homem e o mundo. No âmbito de ensino concreto tanto na universidade quanto na escola. Essas compreensões implicam que se tenham objetivos pedagógicos correspondentes, tais como a participação dos estudantes na constituição do sentido do próprio ensino, em relação aos conteúdos apresentados em forma de temas abertos às experiências com movimentos ou orientados à solução de problemas de movimento, dentre outros. A mesma coisa acontece com relação à escolha dos métodos de ensino a serem utilizados nas mais diferenciadas situações de experiência.

A seguir, apresentamos uma breve visão sobre a teoria da autoeducação, que pode ser atribuída à teoria crítica, assim como à teoria dialógica do movimento, que deve ser atribuída à teoria fenomenológica do movimento. Ao final, esboçamos o conteúdo do seminário didático da disciplina ( $2^{\circ}$ seminário), que trata da transformação didática de um tema do movimento a partir da compreensão pedagógica da educação para a autoeducação e com base na compreensão dialógica do movimento.

8 No Quadro 1 estão apresentados os temas dos seminários que compõem o Módulo 2C. 
Quadro 1 - Seminários no módulo 2 C: Movimento, educação e inclusão

Modulo 2:
Movimento, educação e inclusão
1. Teorias da Educação: teorias do movimentar-se
2. Teoria didática: da transformação didática
3. Educação e inclusão por meio das relações de movimento
4. Campo de movimento (caring, shared e against)

Fonte: os autores

\subsection{A TEORIA DA AUTOEDUCAÇÃO}

Educação é uma parte da socialização geral, isto é, aquele setor de interações conscientes e socialmente regulamentadas nas quais o jovem, no seu processo de desenvolvimento, é qualificado a aprender maneiras culturais de uma sociedade e prosseguir no seu desenvolvimento, e nesse processo de qualificação tornar-se uma pessoa independente e responsável.

Essa introdução foi descrita a partir de duas dimensões relacionadas:

a) como processo de socialização, pelo qual crianças e jovens se desenvolvem como seres sociais;

b) como processo de individualização, pelo qual crianças e jovens se desenvolvem como indivíduos únicos e inconfundíveis.

No contexto dessa socialização geral, a educação representa um campo organizado, planejado, sistematizado e intencional, pelo qual, na nossa sociedade, agências sociais e instituições específicas, como, por exemplo, a família ou a escola, são as responsáveis pela construção cotidiana.

Como um objetivo elementar para a formação dos estudantes da Educação Física, temos o desenvolvimento da capacidade de ação, visto que a educação visa sempre ao indivíduo, ao educando. O seu interesse, entretanto, não pode ser reduzido a uma concepção individualista, contudo deve permanecer claro o seu sentido histórico social, sem renunciar ao seu aspecto individual. A educação deve ser colocada na amplitude normativa que vai da autorrealização individual à emancipação da sociedade. Esses aspectos fundamentam o ideal pedagógico de um sujeito capaz de se tornar atuante por intermédio da educação; um indivíduo que pode operar nos diversos setores existentes da sociedade, mas, ao mesmo tempo, está interessado no desenvolvimento de uma sociedade democrática e é capaz de participar racionalmente dessa mudança. Participação na sociedade como ela é e a problematização das suas estruturas enrijecidas e suas novas perspectivas constituem as duas dimensões dialeticamente limitadas de um conceito pedagógico de capacidade de ação.

A educação que está interessada em um indivíduo capaz de atuar realiza-se por intermédio de uma ação comunicativa. Com isso, entende-se uma ação que não

9 O módulo possui de três a quatro seminários. Cada seminário tem carga horária de 4 a 6 horas por semana. Consideraram-se 15 semanas no semestre. Isso significa que cada seminário tem uma carga horária de 60 a 90 horas por semestre. Um módulo com três seminários tem carga horária total de 180 horas, com quatro seminários uma carga horária total de 270 horas. Também alteramos ligeiramente o conteúdo do módulo em relação à proposta do módulo no livro de Hildebrandt-Stramann, Hatje, Palma e Oliveira (2020). Isso também mostra a possível variabilidade do conteúdo dos módulos. 
tem por objetivo transmitir significado, mas sim visa muito mais à compreensão das diretrizes e objetivos de ação. Mediante a atuação na prática e a reflexão, deve ser possibilitada ao educando uma compreensão do "seu mundo" e da realidade social, uma conscientização das condições, possibilidades e consequências de seu agir: explicação e reflexão próprias em vez da manipulação. Para isso é necessário encarar seriamente as crianças e os jovens como sujeitos que são capazes de agir no seu mundo.

Educar, em princípio, deveria significar promover a autoeducação, que é compreendida aqui como o cerne do modo de entender a educação. "Significa dizer que o jovem se relaciona com pessoas, coisas, termos e acontecimentos disposto a mudanças, na pretensão de ampliar sua vida" (HILDEBRANDT-STRAMANN, 2004, p. 72). Este objetivo não vale só para as aulas de Educação Física nas escolas, mas para a formação universitária também. Em sua vida acadêmica, os estudantes precisam de certa liberdade para organizar e realizar seus estudos. Mas a diferença em relação à escola é que o estudante deve aprender e adotar atitudes com vistas à autoeducação. Para que a capacidade da autoeducação possa se desenvolver, além da atitude, é necessário um "meio ambiente" educativo correspondente. Pelo "meio ambiente" (milieu) entendem-se as relações pessoais entre estudante e professor, baseadas na compreensão e no método de ensino que é determinado por meio da intermediação entre o estudante e a matéria.

\subsection{A TEORIA DIALÓGICA DE MOVIMENTO}

O núcleo dessa visão é que, quando nós, por exemplo, observamos crianças numa aula de Educação Física, não podemos observar movimentos, mas sim sujeitos se movimentando. Não podemos observar um salto, mas sim sujeitos saltando. Temos aqui um sujeito que se movimenta e um mundo (uma situação) com o qual esse movimento está relacionado.

Gordijn, um pedagogo holandês, compreende movimento como uma metáfora. Ele diz: "O movimento humano é um diálogo entre o homem e o mundo"

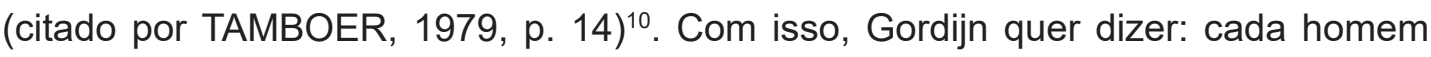
dialoga com seu mundo e, nesse caso, sua linguagem é o movimento. O homem coloca, enquanto se movimenta, perguntas de movimento para seu mundo e recebe respostas de movimento. O mundo não é somente meio ambiente (no sentido físico), mas também os outros homens. O homem entra em contato com as coisas ou com os homens pelo movimento. O movimento, portanto, é compreendido como não sendo do homem e nem do mundo, mas somente do seu relacionamento. Com isso, Gordijn quer expressar que ele não aceita uma separação das instâncias que compõem o acontecimento; por exemplo, uma separação do corpo e do espírito, do motriz e da intenção. A intenção, o sentido, que pré-configuramos em relação à avaliação do resultado final, não pode e não deve ser separada do que acontece nas modificações da posição do corpo pelo movimento. O movimentar-se sempre está cheio de intenções, sempre é um homem que se movimenta. Esse movimento tem um produto individual e especial. Dentro do diálogo, dentro desse jogo de pergunta e resposta, o homem identifica significados motrizes das coisas e dos outros homens. Ele projeta

10 Tamboer chama esta concepção do corpo como "relacional" (TREBELS, 1992, p. 341). 
os significados na pergunta: "O que poderia ser isso?", e recebe o significado na resposta e no processo global do diálogo.

Movimentar-se é só uma forma de relação do homem com o seu mundo, do qual ele recebe os significados. Gordijn acrescenta mais duas formas: pensar e falar. Exemplo: É possível observar a água numa piscina e pensar sobre ela, assim como é possível falar algo sobre a água da piscina e também é possível jogar-se na água. Por isso, o homem vive em diferentes mundos de significados que são cada vez mais determinados pela forma de acesso que ele pode escolher. Assim, o ambiente tem para os homens significados diferentes. Por exemplo, o significado do movimento. Retomando o exemplo de piscina. Somente quando nós ultrapassamos a fronteira entre a beira da piscina e a água e entramos na água é que podemos descobrir e testar os significados do movimento que a água estimula/exige. Estes são, por exemplo, os significados que a água carrega quando nos movimentamos para puxar e/ou empurrar a água para provocar a propulsão (HILDEBRANDT-STRAMANN; HATJE; PALMA; OLIVEIRA, 2020, p. 195-207).

O fato é que o ambiente tem para os homens significados diferentes, que também podemos identificar muito bem no dia a dia. Uma cadeira, por exemplo, tem o significado de um banco de descanso para uma pessoa que estava andando há muito tempo. Para uma criança, a cadeira talvez tenha o significado de um apoio para subir, possivelmente para abrir a porta. Uma pedra pode ter o significado de um objeto para ser carregado, mas quando a lançamos, identificamos o significado de movimento desse objeto.

O mundo não pode ser identificado somente pelo pensar, mas também pelo sentir e pelo movimento. Movimento é um meio de conhecimento e com isso identificamos o seu significado.

Assim como, por exemplo, o paradigma científico-natural de movimento tem suas consequências na configuração do ensino, o paradigma fenomenológico de movimento tem também suas consequências. Aprendemos formas especiais de movimento não pelas explicações ou instruções de movimento pelo professor, mas por meio de um jogo dialético conjunto entre forças estimuladas e forças ativadas. Essas forças determinam as possibilidades e os limites da ação correta. A forma especial de movimento configura-se somente no processo dialógico com as coisas no mundo. A forma não está previamente determinada, mas é resultante do processo desse diálogo.

No processo de aprendizagem, isto é, no desenvolvimento de uma forma adequada, desenvolve-se um sentido para uma execução de movimento correto ou errado. Entendemos que nós, como professores de Educação Física, temos a tarefa de tornar nossos estudantes na universidade e nossos alunos nas escolas responsáveis pela busca de informações que só podem ser encontradas mediante a experimentação ${ }^{11}$. Eles devem buscar caraterísticas de movimentos que são determinadas pelas sensações. A partir da teoria da aprendizagem motora, que se fundamenta na teoria da Gestalt ou na teoria da percepção, sabemos que ninguém

11 A teoria dialógica é também uma base teórica decisiva para a formação universitária nos campos do movimento do módulo 6 e 3 L: 1. Movimentar-se sem e com aparelhos (Ginástica) 2. Lutar (Artes Marciais), 3. Capoeira, 4. Jogar, 5. Jogar em equipes, 6. Movimentar-se na água, 7. Correr, saltar, lançar, 8. Cuidar, compartilhar, opor-se. 
pode tirar dos aprendizes a procura por esse tipo de informação. Exatamente aqui se encontra a fundamentação teórica do movimento para uma aula aberta às experiências de Educação Física (HILDEBRANDT-STRAMANN, 2009; KUNZ, 1991, p. 190).

Essas teorias não se orientam na configuração de processos de ensinoaprendizagem em uma estrutura técnica objetiva de movimento, mas consideram a estrutura subjetiva de ação e a relação de troca entre os seres humanos e o meio ambiente. Chamamos essa concepção de "global" ou "total", porque relaciona o homem com o mundo e vice-versa. Isso é um fundamento caraterístico da existência humana, que Merleau-Ponty (1966) percebe como "estar para o mundo". Também encontramos essa relação indissolúvel no modelo circular da Gestalt (WEIZSÄCKER, 1966). Aqui, perceber e movimentar são uma unidade. Na teoria morfológica de movimento de Meinel e Schnabel (1984), existe uma separação entre aspectos sensitivos (dos analisadores) e motores (os centros motrizes efetores). Segundo Meinel e Schnabel (1984), os dois estão num contexto causal (TREBELS, 1992, p. 340).

Em contraposição a isso, a teoria da Gestalt não fala em um contexto causal do sistema sensitivo e do sistema motor, mas de uma coincidência. Coincidência significa - é isso o que caracteriza a Gestalt - que o perceber acontece ao mesmo tempo em que ocorre o movimento e vice-versa. O perceber influencia o movimento e vice-versa.

Essa unidade de movimento e percepção corresponde, no processo de treinamento, ao contexto significativo do "sentir" e "conseguir". Na teoria de aprendizagem motora fala-se hoje de uma "aprendizagem de movimento controlado por efeito". De acordo com isso, os chamados "stimulus-response-effect-relations" (estímulo-resposta-efeito-relações) são a base do controle motor e da aprendizagem motora (SCHERER, 2018, p. 197). Na combinação do sentir e conseguir será evidenciada a relação do contexto interno com o externo do sujeito, do movimento nas suas percepções e da situação de movimento na sua própria ação de movimento. O problema da aprendizagem motora consiste em aprender o sentir-se na execução do movimento, da forma mais diferenciada e em relação à situação, iniciando o processo de movimentação de modo que o excesso e a falta de energia possam ser equilibrados passo a passo.

\section{A TRANSFORMAÇÃO DIDÁTICA DA PERSPECTIVA DA VISÃO CIENTÍFICA DA DISCIPLINA}

O paradigma fenomenológico apresentado aqui, que na literatura também é referido como uma compreensão dialógica do movimento (TAMBOER, 1979; TREBELS, 2010; KUNZ, 1994; HILDEBRANDT-STRAMANN, 2013), é a base da teoria da pedagogia de movimento para a configuração didática e a discussão dos conteúdos nas aulas de Educação Física, tanto na escola quanto na universidade. Nós denominamos esse processo de transformação didática. No seminário os estudantes recebem a tarefa de desenvolver ideias sobre quais temas de movimento poderiam se configurar como temas nas aulas de Educação Física. 
Em geral, de acordo com a biografia esportiva, por exemplo, eles transformam o tema "saltar" em "salto no atletismo"12. Sem entrar em detalhes, a seguir os professores mostram fotos históricas de pessoas saltando e fotos atuais de crianças e adolescentes saltando. Os estudantes têm a tarefa de classificar essas diferentes formas de saltar: saltar sobre algo, saltar em cima de algo, saltar de cima para baixo, etc. No passo seguinte, as classificações são organizadas de acordo com as intenções do movimento, no espírito do conceito de movimento dialógico. Os alunos podem ver facilmente que, quando as pessoas saltam, o fazem com uma intenção específica: saltar para superar um obstáculo, saltar para chegar em cima de muro, saltar para voar longe etc. "As pessoas se movem intencionalmente, pelo que a situação do movimento determina a intenção de se mover", escreve Gordijn apud Tamboer (1979).

Com essa abordagem geneticamente estruturada ${ }^{13}$, podemos mostrar aos estudantes que suas ideias sobre o salto no atletismo perseguem apenas uma intenção de movimento: mais alto e mais longe ${ }^{14}$. Sua tarefa como futuro professor de Educação Física seria a de oferecer aos alunos a oportunidade de realizar muitas intenções de movimento. Por esse motivo segue a próxima etapa com a tarefa de procurar ou configurar situações de movimento saltando com diferentes intenções de movimento. Este passo pode ser realizado no ginásio, no campo ou num terreno livre. Aqui, por exemplo, os alunos descobrem que:

- O aclive do terreno estimula a saltar para aterrissar no chão após um longo vôo;

- O fosso convida para saltar por sobre ele;

- O trampolim convida a deixarem-se catapultar no ar, etc.

Resumindo: Este segundo seminário é caracterizado por uma mudança constante entre a teoria e a prática refletida teoricamente, em que o objetivo principal é esclarecer a eficácia da teoria da educação e do movimento na prática.

O terceiro seminário deste módulo trata do planejamento de aulas específicas sobre os tópicos de movimento desenvolvidos no segundo seminário e sua realização com os participantes do seminário. Essas tentativas de ensino também são avaliadas teoricamente. No decorrer do curso, eles servem como base para o planejamento das aulas de Educação Física no módulo de "estágio" (Figura 1, módulo 10, estágio 1 e $2 \mathrm{~L})^{15}$.

\section{CONCLUSÃO}

Esta proposta de currículo modularizado é moldada pela intenção dos autores em superar a separação entre ciência da disciplina, didática da disciplina e prática

\footnotetext{
12 Para a análise teórica da ação do movimento "saltar" com base na compreensão dialógica do movimento e para transformação didática do tema "saltar" e a implementação do tema em uma aula de Educação Física, ver Hildebrandt-Stramann; Hatje; Palma; Oliveira (2020, p. 170-183).

13 Para o método de procedimento genético: Beckmann, Hildebrandt-Stramann, Wichmann (2009, p. 34).

14 Neste ponto, uma reflexão sobre essas ideias com base na teoria de sistemas de Luhmann (1984) é apropriada. Nesse contexto, seria analisado o esporte como um campo socialmente construído, que é determinado por duas regras básicas:

- A regra de sobrepujar (no sentido de vencer)

- A regra da comparação objetiva (HILDEBRANDT-STRAMANN, 2013, p. 32).

15 Veja aqui o exemplo de ensino com o tema "Saltar com a vara" (HILDEBRANDT-STRAMANN; HATJE; PALMA; OLIVEIRA, 2020, p. 179-183).
} 
da disciplina que existe nos currículos tradicionais. Nosso entendimento é de que é extremamente difícil para os estudantes combinar as três áreas. Essa separação resulta em diferenças entre as áreas individuais que não podem ser justificadas em termos de teoria científica ou na prática. Além disso, existem as suas experiências biográficas, que geralmente não são compatíveis com os requisitos científicos da universidade. Para a formação profissional dos futuros professores de Educação Física, é necessário combinar essas áreas. Só assim nos parece possível capacitar os alunos a lidar construtivamente com as diferenças na relação teoria-prática do curso para que possam acessar novas perspectivas didáticas sobre o objeto de estudo do seu curso e sobre sua mediação. Acreditamos que isso seja básico e necessário para atender às demandas da educação escolar.

\section{REFERÊNCIAS}

BECKMANN, Heike; HILDEBRANDT-STRAMANN, Reiner. Teoria e prática da oficina de movimento. In: HILDEBRANDT-STRAMANN; Reiner. Educação Física aberta à experiência. Rio de Janeiro: Imperial Novo Milênio, 2009. p. 45-56.

BECKMANN, Heike; HILDEBRANDT-STRAMANN, Reiner; WICHMANN, Klaus. Aprender diante de problemas. In: HILDEBRANDT-STRAMANN; Reiner. Educação Física aberta à experiência. Rio de Janeiro Imperial Novo Milênio, 2009. p. 31-44;

HILDEBRANDT-STRAMANN, Reiner. Educação Física aberta à experiência: uma concepção didática em discussão. Rio de Janeiro: Imperial Novo Milênio, 2009.

HILDEBRANDT-STRAMANN, Reiner. Encenação em Aulas de Movimento na Escola - Três exemplos de aulas. In: KUNZ, Elenor. (org.). Didática da Educação Física. ljuí: Unijuí, 2016. p. 49-66.

HILDEBRANDT-STRAMANN, Reiner. O Esporte Como Fenômeno Social e sua Análise Crítica. In: HILDEBRANDT-STRAMANN, Reiner. Textos pedagógicos sobre o ensino da Educação Física. ljuí: Unijuí, 2013. p. 27-49.

HILDEBRANDT-STRAMANN, Reiner. Quais os rumos da Educação Física? In: KUNZ, Elenor; HILDEBRANDT-STRAMANN, Reiner. (org.). Intercâmbios científicos internacionais em Educação Física e esportes. ljuí: Unijuí, 2004. p. 71-84.

HILDEBRANDT-STRAMANN, Reiner; HATJE, Marli; PALMA, Luciana Erina; OLIVEIRA, Amauri Aparecido Bassoli de. Currículo Modularizado à Formação Inicial em Educação Física: Uma proposta em discussão. ljuí: Unijuí, 2020.

HILDEBRANDT-STRAMANN, Reiner; TAFFAREL, Celi. Nelza Zulke. Formação de Professores e Trabalho Educativo na Educação Física. ljuí: Unijuí, 2017.

KUNZ, Elenor. Apresentação: Pedagogia do Esporte, do Movimento Humano ou da Educação Física? In: KUNZ, Elenor; TREBELS, Andreas (org.). Educação Física críticoemancipatória. ljuí: Unijuí, 2010. p. 11-22.

KUNZ, Elenor. Educação Física: ensino e mudanças. ljuí: Unijuí, 1991.

KUNZ, Elenor. Transformação didático-pedagógica do esporte. 9. ed. ljuí: Unijuí, 1994. 
KUNZ, Elenor; COSTA, Andrize Ramires. Educação Física e Esportes na Escola, revendo teorias e práticas. In: KUNZ, Elenor. (org.). Didática da Educação Física. Ijuí: Unijuí, 2016. p. 13-32.

KUNZ, Elenor; TREBELS, Andreas (org.). Educação Física crítico-emancipatória. ljuí: Unijuí, 2010.

LUHMAN, Niclas. Soziale Systeme. Grundriß einer allgemeinen Theorie. Frankfurt am Main: Suhrkamp,1984.

MEINEL, Kurt. Motricidade I. Teoria da motricidade esportiva sob o aspecto pedagógico. Rio de Janeiro: Ao Livro Técnico, 1984.

MERLEAU-PONTY, Maurice. Phänomenologie der Wahrnehmung. Berlin: Gruyere, 1966.

SCHERER, Hans Georg. Brückenschläge. Interdisziplinäre Forschung zwischen Sportpädagogik und Bewegungswissenschaft. Baltmannsweiler: Schneider, 2018.

TAMBOER, Jan. Sich Bewegen - ein Dialog zwischen Menschen und Welt. sportpädagogik, v. 3, n. 2, p. 14-19, 1979.

TREBELS, Andreas A Concepção Dialógica do Movimento Humano; uma Teoria do "Semovimentar". In: KUNZ, Elenor.; TREBELS, Andrea (org.). Educação Física críticoemancipatória. ljuí: Unijuí, 2010. p. 23-48.

TREBELS, Andreas. Plaidoyer para um diálogo entre teorias do movimento humano e teorias do movimento no esporte. Revista Brasileira de Ciências do Esporte, v. 13, n. 3 , p. 338-344, 1992.

WEIZSÄCKER, Victor von. Der Gestaltkreis. Frankfurt: Suhrkamp, 1966. 
Abstract: This paper debates professionalization in educational sciences and its relationship to college education of Physical Education professionals. Three hypotheses were discussed in the context of curriculum development: i) the difference between science and didactics of a subject; ii) the difference between biographic knowledge, expectations of Physical Education students, and knowledge of the subject that must be conveyed; and iii) the difference between didactics of the subjects and knowledge of teaching or the transformation of didactics knowledge on the subjects into knowledge of teaching. A //modularized curriculum proposal is presented for training Physical Education teachers elaborated in an international curriculum development project. Finally, a Module was //elaborated to present its structure based on the educational theory of self-education and the dialogical theory of movement.

Keywords: Curriculum. Physical Education training. Teacher's Degree.

Resumen: El artículo discute sobre la profesionalización en Ciencias de la Educación y su relación con la formación universitaria de los profesores de Educación Física. Son consideradas tres hipótesis, que deben ser resueltas en el contexto del desarrollo del currículo: la diferencia entre ciencia de la asignatura y didáctica de la misma; la diferencia entre el conocimiento biográfico, las expectativas de los estudiantes de Educación Física y el conocimiento de la asignatura que debe ser transmitido; y la diferencia entre la didáctica de las asignaturas y el conocimiento de la enseñanza o la transformación del conocimiento didáctico de las asignaturas en conocimiento de la enseñanza. Para ejemplificar la discusión, se presenta una propuesta de currículo modular para la formación de profesores de Educación Física, elaborada por los autores durante el desarrollo de un proyecto curricular internacional y, en seguida, de un módulo que tiene como objetivo mostrar su estructura basada en la teoría educacional de la autoeducación y en la teoría dialógica del movimiento.

Palabras clave: Currículo. Formación en Educación Física. Licenciatura. 


\section{LICENÇA DE USO}

Este é um artigo publicado em acesso aberto (Open Access) sob a licença Creative Commons Atribuição 4.0 Internacional (CC BY 4.0), que permite uso, distribuição e reprodução em qualquer meio, desde que o trabalho original seja corretamente citado. Mais informações em: http://creativecommons.org/licenses/by/4.0

\section{CONFLITO DE INTERESSES}

Os autores declararam que não existe nenhum conflito de interesses neste trabalho.

\section{CONTRIBUIÇÕES AUTORAIS}

Reiner Hildebrandt-Stramann: Conceituação e redação - revisão e edição (40\%); Amauri Aparecido Bássoli de Oliveira: Conceituação e redação - revisão e edição $(20 \%)$;

Marli Hatje: Conceituação e redação - revisão e edição (20\%);

Luciana Erina Palma: Conceituação e redação - revisão e edição (20\%).

\section{FINANCIAMENTO}

O presente trabalho não recebeu nenhum apoio financeiro.

\section{COMO REFERENCIAR}

HILDEBRANDT-STRAMANN, Reiner; OLIVEIRA, Amauri Aparecido Bássoli de; HATJE, Marli; PALMA, Luciana Erina. A formação do professor de educação física: para além da didática das disciplinas. Movimento (Porto Alegre), v.27, p. e27021, jan./dez. 2021. Disponível em: https://seer.ufrgs.br/Movimento/article/view/106849. Acesso em: [dia] [mês abreviado]. DOI: https://doi.org/10.22456/1982-8918.106849

\section{RESPONSABILIDADE EDITORIAL}

Alex Branco Fraga*, Elisandro Schultz Wittizorecki ${ }^{*}$, Ivone Job*, Mauro Myskiw*, Raquel da Silveira *

*Universidade Federal do Rio Grande do Sul, Escola de Educação Física, Fisioterapia e Dança, Porto Alegre, RS, Brasil. 